\title{
PERAN AUGMENTED REALITY DALAM MENINGKATKAN VISITOR EXPERIENCE GENERASI MILENIAL DI MUSEUM BERTEMA
} TEKSTIL INDONESIA

\author{
Sandy Rismantojo ${ }^{1}$ dan Jesslyn Valenska ${ }^{2}$ \\ 1,2Program Studi Desain Komunikasi Visual, Fakultas Seni Rupa dan Desain, Universitas Kristen Maranatha \\ jl. Suria Sumantri no. 65 Bandung, Indonesia \\ ${ }^{1}$ sandy.rismantojo@art.maranatha.edu, 2jvaleskaa19@gmail.com
}

\begin{abstract}
Abstrak: Indonesia memiliki berbagai kekayaan budaya, salah satunya adalah batik yang dapat ditemukan hampir di tiap daerah dan memiliki kekhasannya masing-masing. Keanekaragaman batik serta motif-motifnya yang memiliki nilai filosofi menjadi penting untuk didokumentasikan, dijaga dan dilestarikan sehingga muncul museum khusus batik atau tekstil khas Indonesia seperti Museum Tekstil Jakarta dan Museum Batik Pekalongan. Museum adalah lembaga yang berfungsi sebagai tempat pengamanan, pendataan, perawatan, dan pengelolaan benda bukti material hasil budaya manusia untuk mendukung usaha pelestarian dan perlindungan kekayaan budaya bangsa. Sayangnya museum di Indonesia seperti hidup segan mati tak mau, pengunjung yang terus berkurang dan minimnya dana menjadi beberapa penyebab museum menjadi tidak menarik untuk dikunjungi. Banyak museum yang melupakan bahwa visitor experience sangat penting untuk dibangun, dikelola dan dijaga kekonsistennya. Tulisan ini difokuskan pada visitor experience berdasarkan tampilan dari desain komunikasi visual, desain interior, dan exhibition design. Perbandingan museum difokuskan pada museum-museum yang ada di Indonesia, Malaysia serta Singapura, menggunakan metoda deskriptif komparatif dengan observasi langsung ke beberapa museum yang memiliki kesamaan tematik yaitu mengenai batik dan tekstil. Hasil observasi melihat kelebihan dan kekurangan dari museum-museum tersebut sehingga memberikan rekomendasi pengembangan untuk membangun visitor experience yang positif, dengan memanfaatkan teknologi seperti augmented reality agar kunjungan ke museum menjadi lebih menarik, interaktif sehingga membantu proses transfer informasi yang lebih jelas dan mudah diterima.
\end{abstract}

Kata kunci: augmented reality, batik, museum, visitor experience

Abstract: Indonesia has many varieties of cultural wealth, one of which is batik that can be found in almost every region and has its own uniqueness. The diversity of batik and its motifs which have philosophical values are very important to be documented, maintained and preserved. Museum is an institution that manages the storage, security, maintenance, and utilization of material evidence of human cultural products in order to support, protect 
and preserve the nation's cultural wealth. Indonesia has several specific batik or textile museums, for examples, the Jakarta Textile Museum and the Pekalongan Batik Museum. Unfortunately, nowadays the fate of most museums in Indonesia is uncertain. The decreasing of the visitor numbers, lack of funds, or outdated museum design are the reasons these museums become unattractive to be visited. Many museums have forgotten that visitor experience is very important to be built, managed and maintained consistently. This paper is focused on the visitors' experience based on the appearance of visual communication design, interior design, and exhibition design. Museum comparison focuses on museums in Indonesia, Malaysia and Singapore, by using a descriptive comparative method with direct observation to several batik or textile museums. The observations will determine the advantages and disadvantages of these museums in order to build a positive visitor experience, by utilizing technology such as augmented reality so that museums become interesting, interactive, and effective in helping the process of appealing information exchange.

Keywords: augmented reality batik, museum, visitor experience

\section{PENDAHULUAN}

Indonesia dikenal memiliki kekayaan budaya yang beraneka ragam dan unik. Kekayaan budaya inilah yang dapat menjadi modal untuk memajukan ekonomi kreatif di berbagai wilayah. Salah satu industri kreatif yang sudah lama berkembang dan sudah mengalami jatuh bangun adalah industri batik. Indonesia memiliki berbagai jenis batik, contohnya batik di Pulau Jawa yang terdiri dari batik pedalaman dan batik pesisir. Kedua batik tersebut memiliki ciri khasnya tersendiri yang menarik untuk dikenal. Contoh batik pedalaman adalah batik Solo dan Yogyakarta sementara contoh batik pesisir adalah batik Pekalongan, batik Kudus, dan batik Lasem. Karena perkembangan batik di Indonesia sudah sangat panjang maka terdapat beberapa museum batik yang memamerkan batik-batik dengan kualitas yang sangat baik, yang dapat kita temukan di museum Tekstil Jakarta atau Museum Batik Pekalongan.

Tetapi saat ini banyak museum yang mengalami permasalahan yang sama yaitu dianggap kuno, kurang terawat, fasilitas yang tidak diperbaiki ataupun ditambah, membosankan, dan adanya anggapan bahwa museum hanya untuk 
anak TK dan SD maka tidak mengherankan jika banyak museum yang masih sepi atau kekurangan pengunjung. Dan hal-hal tersebut pulalah yang dihadapi oleh museum khusus batik dan tekstil selain kurangnya dana pengelolaan. Padahal peran museum itu sangat penting sebagai tempat pelestarian dan penyampaian ilmu. Mengacu pada definisi museum oleh Kemendikbud bahwa museum sebagai lembaga permanen yang bersifat tidak komersial, bertujuan untuk melestarikan koleksi yang bersifat bendawi, dan mengkomunikasikannya kepada khalayak ramai. Oleh karena itu sangat penting bagi para pengelola museum untuk memperhatikan visitor experience (pengalaman pengunjung) agar para pengunjung dapat memperoleh informasi dengan jelas, tersampaikan dengan menarik dan menambah pengetahuan serta akhirnya merekomendasikan museum tersebut ke teman dan keluarganya.

Target utama pengunjung museum saat ini dapat dikatakan adalah generasi milenial yang pada tahun 2017 menguasai 33,75\% persen dari total jumlah penduduk usia produktif di Indonesia, mereka merupakan generasi yang sangat terpapar teknologi dan fasih pula. Generasi inilah yang diharapkan dapat mengelola dan mengembangkan kekayaan budaya Indonesia. Diharapkan dengan mengunjungi museum bertema tekstil, mereka dapat terinspirasi, belajar dan bahkan mengembangkan pengetahuan mereka mengenai tekstil khas Indonesia dan dapat memanfaatkannya untuk mengembangkan industri-industri kreatif Indonesia

Indonesia sudah memiliki berbagai jenis museum yang tersebar di banyak kota namun hampir semua museum yang ada di Indonesia sedang memiliki masalah yang sama, seperti kunjungan yang menurun atau tidak ada peningkatan, kurangnya kreativitas pengembangan program pameran serta pengemasan yang unik dari pengelola untuk menarik minat pengunjung sehingga banyak museum yang tampilan dan materinya sama sejak awal pembukaan, kesulitan dalam 
pendanaan atau banyaknya anggapan bahwa mengunjungi museum itu membosankan dan tidak menyenangkan. Walaupun Gerakan Nasional Cinta Museum sudah dicanangkan sejak tahun 2010 lalu, nyatanya generasi milenial belum banyak yang tertarik berkunjung ke museum karena museum masih dianggap kurang mengakomodasi minat anak muda. Para pengunjung museum, terutama anak muda, lebih suka datang untuk berswafoto bersama teman-teman, hanya sedikit dari mereka yang benar-benar ingin belajar di museum (Djunaedi, 2015).

Dari pernyataan di atas dapat dilihat bahwa visitor experience menjadi elemen penting agar masyarakat tertarik datang ke museum. Sebenarnya saat ini sudah banyak museum di Jakarta atau Bandung yang sangat menarik untuk dikunjungi tetapi bila visitor experience tetap tidak dikelola dengan baik maka pengalaman berkunjung yang dialami menjadi tidak berkesan bahkan cenderung membosankan. Maka perlu dikembangkan program-program yang unik dan menarik oleh pengelola museum serta museum harus memanfaatkan teknologi terkini dan memiliki tampilan yang selalu up to date, agar mampu menarik minat generasi milenial.

Indonesia memiliki museum yang fokus pada kekayaan budaya terutama batik, tenun, kain-kain khas indonesia seperti Museum Tekstil Jakarta, Museum Batik Pekalongan, Museum Trupark di Cirebon dan Museum Batik Yogyakarta. Museum-museum ini menampilkan berbagai jenis batik dari berbagai wilayah Indonesia yang terawat dengan baik sehingga menjadikannya tempat yang menarik untuk dikunjungi dan dapat menambah pengetahuan tentang batik di Indonesia. Namun berdasarkan hasil kunjungan langsung serta observasi, hampir keempat museum ini membawa kesan yang sama, yaitu tua, membosankan, kurang terawat dan ketinggalan jaman. Maka diperlukan suatu inovasi yang melibatkan perkembangan teknologi yang dapat menyebabkan visitor experience 
menjadi mengesankan sehingga proses pembelajaran menjadi lebih menarik dan mudah dicerna. Dalam tulisan ini akan difokuskan pada museum batik atau tekstil di Jakarta, Pekalongan, Cirebon, Yogyakarta dan dibandingkan dengan Museum Tekstil di Kuala Lumpur dan Museum Peranakan di Singapore.

\section{METODE PENELITIAN}

Metode yang digunakan dalam penulisan ini adalah deskriptif-komparatif. Pengamatan (observasi) dilakukan langsung ke Museum Tekstil Jakarta, Museum Trupark Cirebon, Museum Batik Pekalongan, Museum Batik Yogyakarta, untuk museum di dalam negeri serta museum di luar negeri yang diwakili oleh National Textile Museum Kuala Lumpur Malaysia dan Peranakan Museum Singapore untuk membandingkan secara langsung desain dari materi atau informasi yang ditampilkan, desain pameran, signage museum, dan teknologi terkini yang digunakan. Museum-museum tersebut dipilih karena memiliki kesamaan tema yaitu tekstil seperti batik atau/dan tenun. Selain itu penulis juga melakukan studi pustaka baik dalam bentuk buku, e-jurnal, serta disertasi. Untuk melengkapi data, penulis melakukan dua kali online survey dengan menggunakan Google Form mengenai museum dan karya seni berjudul Decoding\#1 yang menggunakan teknologi Augmented Reality. Survey ini menyasar target audience yang difokuskan kepada generasi milenial karena saat ini mereka adalah generasi produktif dengan jumlah penduduk terbesar di Indonesia. Penelitian ini kemudian dilengkapi dengan teori-teori mengenai museum, visitor experience, augmented reality $(A R)$, dan Desain Komunikasi Visual.

\section{HASIL DAN DISKUSI}

Di masa lalu, museum dikenal dengan pelayanan atau perlakuan yang dianggap dingin kepada para pengunjung. Anggapan itu muncul karena museum dirasakan hanya memberikan sedikit atau tanpa pengarahan ketika pengunjung 
datang ke museum. Beberapa pegawainya hanya ditugaskan untuk menyambut dan memberikan pengarahan yang seadanya saja sehingga dianggap kurang membantu. Selain itu upaya museum untuk memberikan pengalaman kunjungan yang berarti di dalam ingatan pengunjung juga dirasakan kurang. Tetapi saat ini situasi telah berubah dalam perkembangan sejumlah museum. Museum-museum sudah melakukan penelitian mengenai persepsi, sikap, dan karakteristik dari para pengunjung serta bukan pengunjung, dan juga mendalami komentar-komentar para pengunjung tentang pengalaman mereka.

Penelitian-penelitian tersebut sangat membantu para pengelola museum untuk merancang kembali program-program pameran agar dapat mencapai tingkat yang lebih tinggi dari kepuasan pengunjung. Para pengelola museum harus sadar dan menghargai fakta bahwa kualitas pengalaman pengunjung ditentukan dari apakah pengunjung akan mengunjungi lagi atau akan merekomendasikan museum tersebut kepada pengunjung potensial lainnya (Kotler \& Kotler, 1998:43, seperti dikutip oleh Nasution, 2014). Pernyataan tersebut mengungkap pentingnya museum melakukan suatu riset, khususnya terhadap pengunjung agar museum dapat mengembangkan program museum yang menarik dan berkesan agar pengalaman pengunjung (visitor experience) menjadi lebih positif.

Pengertian kata museum menurut Lembaga Permuseuman Internasional (ICOM) adalah lembaga permanen non-profit yang melayani masyarakat dan perkembangan lingkungannya, terbuka untuk umum, yang berfungsi untuk menghimpun, merawat, meneliti, mengkomunikasikan, dan memamerkan warisan sejarah kemanusiaan yang bersifat bendawi dan nonbendawi beserta lingkungannya, untuk tujuan pendidikan, penelitian, dan hiburan (Akbar, 2010 dalam Nasution, 2014). Sementara berdasarkan Peraturan Pemerintah Nomor 66 Tahun 2015 tentang museum yang menyatakan bahwa museum adalah lembaga yang berfungsi melindungi, mengembangkan, memanfaatkan koleksi, dan 
mengkomunikasikan kepada masyarakat. Pengertian mengenai koleksi adalah benda cagar budaya, bangunan cagar budaya, dan/atau struktur cagar budaya dan/atau bukan cagar budaya yang merupakan bukti material hasil budaya dan/atau material alam dan lingkungannya yang memiliki arti penting bagi sejarah, ilmu pengetahuan, pendidikan, agama, kebudayaan, teknologi, dan/atau pariwisata. Museum juga mempunyai tugas dalam hal pengkajian, pendidikan dan kesenangan atau hiburan.

Dapat disimpulkan arti dari kata museum adalah suatu lembaga nonprofit yang terbuka untuk umum di mana koleksi warisan seni budaya milik manusia, alam dan lingkungannya dari suatu rentang waktu dan wilayah tertentu didata, disimpan, dikelola, dirawat dan dipamerkan untuk dimanfaatkan bagi berbagai aktivitas masyarakat seperti pendidikan, rekreasi, hiburan, dan kegiatan penelitian baik yang dilakukan oleh kalangan museum sendiri maupun pengunjung yang datang untuk penelitian.

Museum pada abad ke-20 memiliki fungsi sebagai tempat yang digunakan untuk belajar dan mengkomunikasikan cara belajar secara menarik. Orang yang datang ke museum pada masa itu menempatkan dirinya sebagai murid yang siap menerima ilmu baru dari museum. Namun ketika mulai memasuki abad ke-21, kebiasaan museum pada abad ke-20 mulai mengalami masalah karena orangorang yang datang ke museum menempatkan diri mereka sebagai konsumen. Hal ini menyebabkan diharuskannya terjadi beberapa perubahan pada museum agar dapat diterima oleh orang-orang pada masa kini.

Tantangan yang dihadapi oleh museum-museum saat ini adalah bagaimana membangun identitas dan misi dari museum, membangun audience, dan menarik investor. Untuk memenuhi tantangan tersebut, museum harus berubah dari museum yang menempatkan diri sebagai sistem komunikasi untuk 
memberi ilmu menjadi museum yang menempatkan dirinya sebagai pameran yang memperlihatkan gagasan-gagasan baru (Kotler \& Kotler, 2000)

Museum modern harus dapat menempatkan diri sebagai tempat yang dapat memberikan sesuatu yang baru bagi pengunjung yang datang. Menurut Deirdre Stam (seperti dikutip dari Hui-Chuan et al, 2006), museum harus menerapkan teknik baru, yaitu metode baru untuk mengerti keadaan sosial sekitar, cara baru untuk menguji kebutuhan pengunjung dan responnya, struktur organisasi dan manajemen baru untuk dapat masuk ke dalam relasi yang baru dan dinamis, cara baru untuk mengevaluasi produktivitas, pola komunikasi baru, serta pendekatan baru. Teknik tersebut dibutuhkan karena dewasa ini orang yang datang ke museum mengharapkan pengalaman yang baru. Pengalaman tersebut dapat "dijual" oleh museum untuk mendapatkan keuntungan dan menyebarkan informasi yang ingin museum tersebut sampaikan. Menurut Pekarik, et al (seperti dikutip dari Hui-Chuan et al, 2006), pengalaman yang dapat diperoleh terbagi menjadi 4, yaitu pengalaman objek, pengalaman kognitif, pengalaman introspektif, dan pengalaman sosial. Menurut Neil Kotler dan Philip Kotler, contoh pengalaman yang dapat diberikan museum antara lain rekreasi, pelajaran sosial, pengalaman estetik, pengalaman perayaan, dan pengalaman yang membuat takjub. Semua pengalaman di atas bisa didapatkan dengan menerapkan tiga strategi, yaitu meningkatkan pengalaman datang ke museum, melayani komunitas, dan memberikan hiburan.

Museum saat ini harus lebih interaktif. Hal ini dapat membuat perubahan sudut pandang dari museum yang berpusat ke kurator menjadi berpusat ke pengunjung. Pengalaman dan kepuasan pengunjung lah yang diutamakan ketimbang kepuasan dari kurator. Walaupun seperti itu, museum harus tetap dapat menyampaikan informasi yang ingin diberikan. Informasi yang diberikan tersebut tidak diberikan secara sepihak dari museum itu saja, tetapi konsumen 
pun memberikan tanggapan balik agar terjadi komunikasi 2 arah. Hal ini akan lebih berkesan dan tidak membosankan bagi konsumen tersebut. Museum juga harus senantiasa berevolusi mengikuti budaya yang dinamis. Sehingga museum dapat memberikan informasi yang sama tetapi dengan pengalaman yang berbeda sesuai dengan budaya yang berlaku. Intinya adalah, museum yang baik harus dapat melihat dari sudut pandang pengunjung agar dapat memberikan kepuasan dan pengalaman yang maksimal.

Target pengunjung yang sebaiknya menjadi fokus utama dari setiap museum adalah generasi milenial yang saat ini berjumlah 33,75\% dari total jumlah penduduk produktif di Indonesia. Oleh sebab itu sangat penting untuk mengetahui secara seksama tentang karakteristik dari generasi ini. Menurut beberapa penelitian yang sudah dilakukan, dapat disimpulkan bahwa generasi milenial adalah warga masyarakat yang lahir di rentang waktu antara tahun 1981 hingga tahun 2000. Generasi milenial merupakan generasi yang kreatif dan inovatif dikarenakan oleh keterikatannya dengan teknologi yang sedang berkembang pesat sehingga dapat menjadi pribadi yang lebih efisien dan produktif. Generasi ini dikenal memiliki pola pikir yang terbuka, kritis, bebas, dan berani. Itu merupakan modal yang berharga untuk menumbuhkan peluang dan kesempatan berinovasi (Kementerian Pemberdayaan Perempuan dan Perlindungan Anak, 2018).

Menurut studi yang dilakukan pada tahun 2018 oleh Kementerian Pemberdayaan Perempuan dan Perlindungan Anak menyebutkan bahwa perbedaan yang jelas antara generasi milenial, generasi $\mathrm{X}$ dan generasi Baby Boomers adalah penggunaan teknologi. Generasi milenial tidak saja menggunakan teknologi untuk sekedar untuk komunikasi, tapi juga sebagai alat studi, mencari data, hiburan dan untuk berbisnis. Saat ini penggunaan telepon seluler sudah 
hampir dilakukan oleh semua orang, tetapi generasi milenial yang lebih unggul dan cakap dalam memanfaatkan teknologi telepon seluler.

Saat ini yang harus diperhatikan bahwa museum yang masih menggunakan cara-cara konvensional, sudah mulai ditinggalkan oleh pengunjung. Hal ini disebabkan karena museum konvensional kurang menggunakan media digital yang saat ini sedang berkembang sangat pesat. Media digital (digital media) merupakan kombinasi dari elemen teks, grafis, visual, audio, video, dan animasi yang kemudian dimanipulasi secara digital (Vaughan, 2004). Media digital dapat memperlihatkan koleksi museum yang telah digitalisasi dan memberikan informasi yang berguna bagi pengunjung. Selain itu, media digital juga dapat memberikan wawasan dalam bentuk demonstrasi cara pembuatan objek di museum tersebut dalam bentuk video. Keuntungan yang didapatkan dari museum yang menggunakan media digital antara lain (Hong, 1995, seperti dikutip Bertalya, 2014) dapat menyimpan koleksi original museum terutama yang sudah rapuh untuk jangka waktu yang lama karena aman dari sentuhan pengunjung, koleksi museum dapat dimanipulasi dan didistribusikan secara mudah, kemudian dapat diakses oleh lebih dari satu pengguna pada waktu bersamaan, bahkan dari seluruh penjuru dunia, serta dapat dilihat dengan kecepatan yang tinggi dan dengan cara yang memikat.

Augmented Reality adalah teknologi yang menyatukan benda maya dua dimensi dan/atau tiga dimensi ke dalam sebuah dunia fisik lalu memproyeksikan benda-benda maya tersebut dalam waktu nyata. Augmented Reality tidak bertujuan untuk sepenuhnya menggantikan kenyataan, namun hanya melengkapi atau menambahkan kenyataan (Muntahanah, Toyib, dan Ansyori, 2017). Kroll (2016) mengemukakan definisi Augmented Reality secara fungsi bahwa "Augmented reality (AR) menciptakan lapisan informasi digital di atas dunia fisik yang dilihat melalui perangkat Android atau iOS. Berbeda dengan Virtual Reality 
(VR) yang merupakan lingkungan simulasi digital yang mereplikasi dunia fisik." Secara singkat, AR menggabungkan yang nyata dan virtual, dalam suatu interaksi yang berlangsung atau terjadi dalam waktu nyata, dimana konten virtual diselaraskan dengan lokasi dan objek tertentu (Marques, n.d.). Beberapa museum mulai memasukan teknologi $A R$ untuk mengembangkan museum tersebut. Museum interaktif memberikan pengunjung pengalaman yang jauh dari kata pasif melalui Story telling dan media experience.

Teknologi telepon genggam mendapat perhatian yang sangat besar untuk saat ini. Hampir seluruh pengunjung museum memiliki telepon genggam. Hal ini dapat dimanfaatkan oleh museum dengan mengaplikasikan teknologi AR di telepon genggam agar para pengunjung bisa berinteraksi dengan koleksi di museum sesuai dengan ketertarikan masing-masing pengunjung, apalagi bila diterapkan dalam bentuk game dengan desain yang menarik sehingga lebih interaktif. Pengaplikasian teknologi AR dapat menggabungkan pengalaman dan interaksi, sehingga dapat membantu pembelajaran menjadi lebih mudah. Maka dengan penerapan teknologi ini maka dapat menjadi daya tarik bagi generasi milenial untuk mengunjungi museum serta memanfaatkannya untuk mencari data, hiburan, menginspirasi.

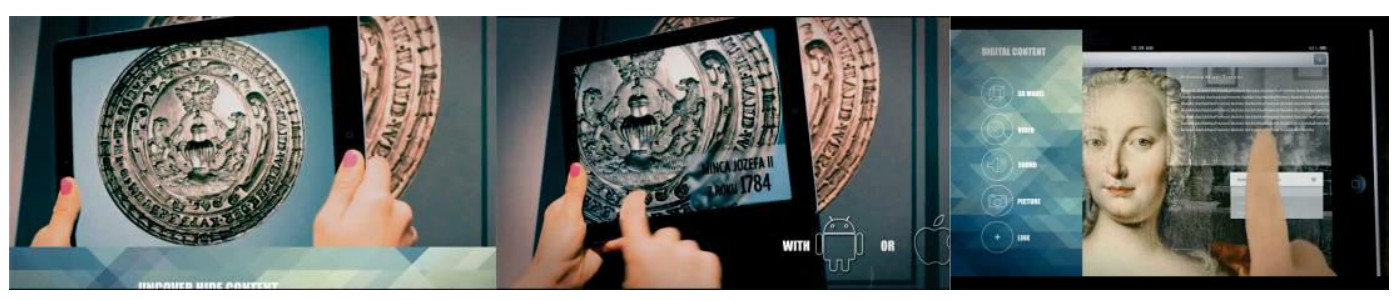

Gambar 1 Screenshot dari Augmented Reality App for Museums Strategic Sumber: https://www.youtube.com/watch?v=yzSqDYzabkg, 2019 
Desain Komunikasi Visual menggabungkan fungsi huruf dan gambar atau image untuk mengkomunikasikan sebuah pesan, dan dalam hal ini memegang peranan penting dalam menginformasikan isi tujuan dari sebuah pameran. Selain itu juga menjadi jembatan dalam interpretasi materi pameran antara kurator pameran dengan masyarakat. Hal utama yang harus diperhatikan baik para pengelola museum dan desainer adalah selain mendesain tampilan visual yang mencakup elemen-elemen grafis seperti pemilihan fonts, visual, dan warna adalah bagaimana membangun storyline yang menarik sehingga dapat mengikat perhatian dan minat dari para pengunjung.

Storyline adalah deskripsi tertulis dari suatu konten naratif dari materi pameran dalam museum. Mencari data untuk membentuk suatu alur cerita yang logis dan menarik membutuhkan penelitian yang mendalam tentang suatu subjek. Proses ini akan menghasilkan kumpulan informasi baik teks maupun visual dalam jumlah yang banyak yang pada awalnya dapat nampak berantakan dan membingungkan. Membuat sebuah diagram informasi adalah salah satu cara yang sangat berguna untuk menemukan ide-ide untuk tema dan alur cerita dari kumpulan informasi yang berantakan dan membingungkan tersebut. Akhirnya informasi-informasi tersebut dapat diatur ke dalam hirarki cerita yang logis (Locker, 2011).

Peran utama dari seorang desainer pameran adalah untuk menciptakan atau merancang suatu suasana dalam bentuk tiga dimensi yang menarasikan suatu cerita yang dapat menerangkan suatu koleksi, atau suatu ide. Desainer akan memilih dan menggunakan berbagai macam media dan teknologi, sering juga meminjam teknologi dari disiplin ilmu lain dengan tujuan untuk lebih efektif mengkomunikasikan suatu pesan di dalam ruang dan waktu. Dengan dibantu storyline maka museum dapat membangun komunikasi antara pengunjung 
dengan materi pameran yang ditampilkan sehingga dapat diapresiasi dan baik bahkan secara emotional pesan yang dapat ditangkap dengan baik (Locker, 2011).

Salah satu elemen penting yang harus diperhatikan dalam mendesain suatu museum atau pameran adalah signage/penunjuk arah. Signage untuk arah orientasi adalah desain yang penting untuk mengatur pengunjung pameran dan bagaimana mereka mengerti secara keseluruhan alur perjalanan mereka dalam area museum. Semua signage, baik sebagai penunjuk arah atau memberi instruksi, sudah seharusnya didesain sebagai bagian dari kesatuan grafis yang digunakan di keseluruhan pameran museum. Yang paling penting, signage dan arah harus mudah dimengerti secara jelas, tidak memiliki dua makna, desain yang sederhana dan dapat dicerna secara cepat serta tidak membingungkan.

Untuk penelitian ini, juga penulis menyebarkan kuesioner secara online mengenai museum dengan menggunakan Google Form yang dijawab oleh 66 responden yang terdiri dari $51,5 \%$ perempuan dan $48,5 \%$ pria dengan range umur 18-25 dan 26 -35 sebanyak $69,7 \%$ yang sebagian besar merupakan generasi milenial. Kesimpulan dari hasil survey tersebut adalah sebagai berikut, sebanyak kurang lebih 92,4 \% adalah pengguna aktif media sosial seperti Instagram, Whatsapp, dan Line dimana 54,5\% menyatakan bahwa mengetahui keberadaan atau mendapatkan informasi tentang suatu museum dari Instagram selain mendapatkan anjuran dari teman atau saudara. Sebanyak $53 \%$ menyatakan hal yang menyebabkan mereka tidak tertarik mengunjungi museum adalah lokasi, cenderung membosankan, dan terkesan kuno. Mereka juga berpendapat bahwa banyak museum yang tidak terawat, display pameran yang tidak menarik, alur informasi yang membingungkan dan koleksi museum yang tidak ter-update. Namun $83 \%$ setuju bahwa museum adalah tempat yang berfungsi sebagai sumber sejarah, menjaga kekayaan budaya, dan sarana edukasi. $96 \%$ berpendapat bahwa penggunaan teknologi Augmented Reality dapat membuat pengalaman 
mengunjungi museum menjadi lebih menarik karena akan membantu dalam menjelaskan objek-objek museum, selain itu apabila didesain dalam bentuk game akan menjadi lebih menyenangkan. 91\% setuju apabila terdapat aplikasi khusus museum Indonesia versi android akan sangat membantu mereka dalam mengenali dahulu dan kemudian berkunjung ke museum-museum.

Selain itu masukan-masukan langsung tentang museum dari para peserta survey dapat disimpulkan sebagai berikut, museum sebaiknya selalu up to date dalam menampilkan materi pameran, tampilan display lebih interaktif, rekreatif/fun, instagramable, storyline yang runut serta mudah dipahami, dan ditambah penerapan fungsi teknologi $A R$, perkembangan dan dukungan masih sangat tergantung pada dana karena tidak dianggap menguntungkan, ketertarikan masyarakat serta pemahaman manfaat museum masih kurang atau sebaliknya museum belum dimanfaatkan secara maksimal sebagai wadah untuk transfer pengetahuan oleh masyarakat, dan kurangnya kesadaran dari pihak museum untuk mengemas informasinya menjadi informatif singkat, padat, jelas, menarik, dan edukatif

Museum-museum yang diobsevasi langsung adalah Museum Tekstil Jakarta, Museum Trupark Cirebon, Museum Batik Pekalongan, Museum Batik Yogyakarta serta National Textile Museum Kuala Lumpur dan Peranakan Museum Singapore. Observasi yang dilakukan difokuskan pada desain grafis mencakup layout informasi, visual, dan signage, exhibition design, storyline, dan penggunakan teknologi terkini. 

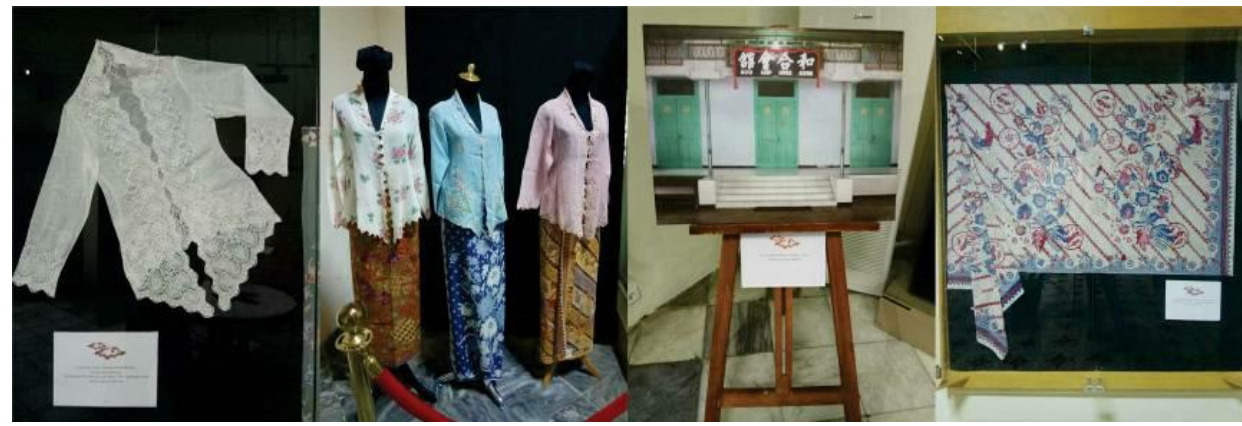

Gambar 2 Museum Tekstil Jakarta

Sumber: Rismantojo dan Valenska, 2018

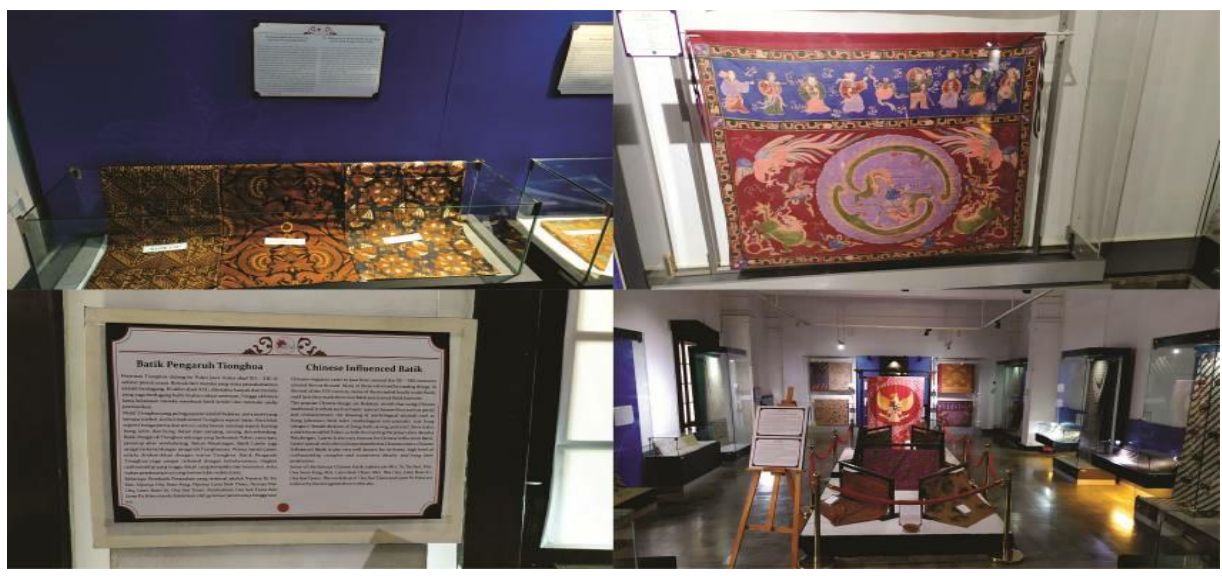

Gambar 3 Museum Batik Pekalongan

Sumber: Rismantojo dan Valenska, 2019

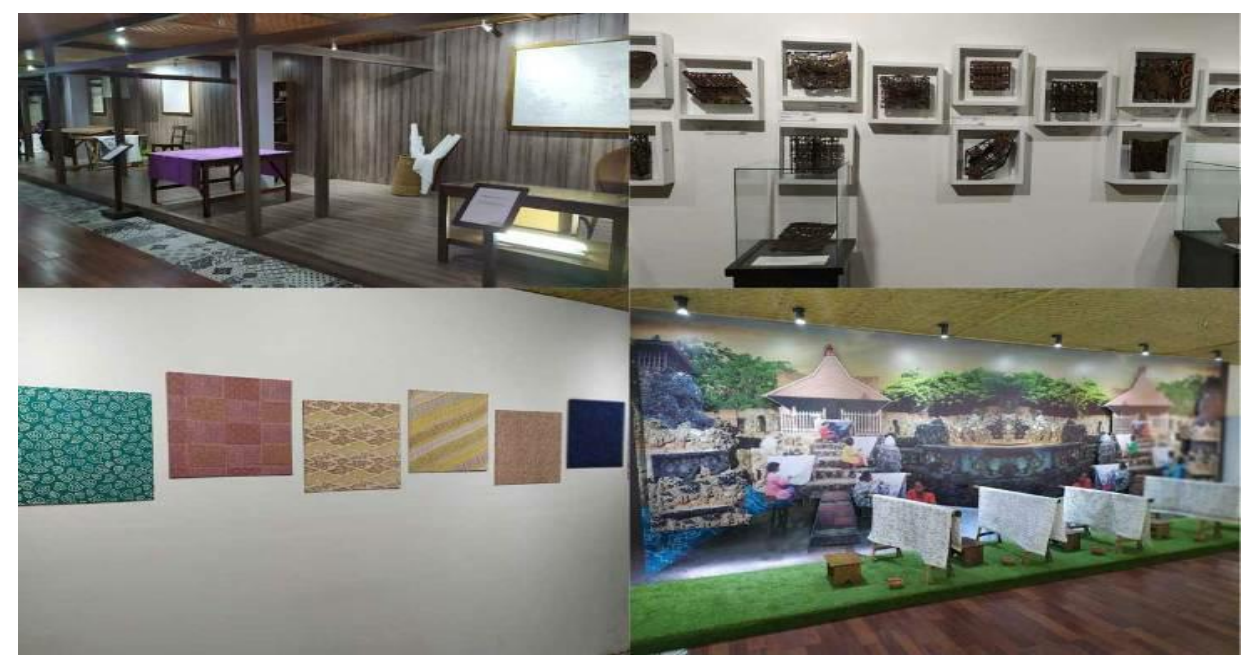

Gambar 4 Museum Trupark Cirebon

Sumber: Rismantojo dan Valenska, 2019 


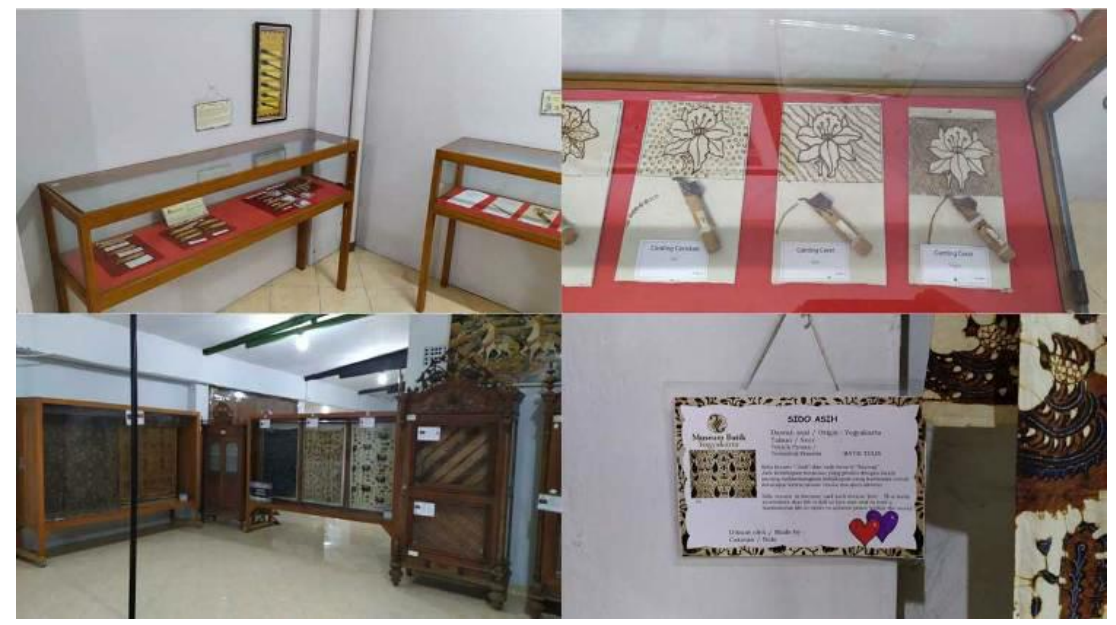

Gambar 5 Museum Batik Yogyakarta

Sumber: Rismantojo dan Valenska, 2019

Tabel 1 Perbandingan elemen-elemen desain di museum bertema tekstil di Indonesia

\begin{tabular}{|c|c|c|c|c|c|c|c|}
\hline Museum & $\begin{array}{c}\text { Grafis } \\
\text { Informasi }\end{array}$ & Signage & $\begin{array}{l}\text { Layout } \\
\text { Gedung }\end{array}$ & $\begin{array}{c}\text { Media } \\
\text { Digital }\end{array}$ & $\begin{array}{c}\text { Story } \\
\text { telling }\end{array}$ & Guide & $\begin{array}{c}\text { Museum } \\
\text { Shop }\end{array}$ \\
\hline $\begin{array}{c}\text { Tekstil } \\
\text { Jakarta } \\
\text { Bangunan } \\
\text { Antik } \\
\text { Bersejarah }\end{array}$ & $\begin{array}{c}\text { Jelas } \\
\text { namun } \\
\text { konvensio } \\
\text { nal }\end{array}$ & $\begin{array}{c}\text { Kurang } \\
\text { jelas }\end{array}$ & $\begin{array}{c}3 \text { gedung: } \\
\text { Pameran } \\
\text { khusus, } \\
\text { Koleksi } \\
\text { utama, } \\
\text { \&Worksho } \\
\text { p batik. } \\
\text { Layout } \\
\text { cenderung } \\
\text { sempit }\end{array}$ & $\begin{array}{c}\text { Tidak } \\
\text { ada }\end{array}$ & Tidak ada & $\begin{array}{c}\text { Tidak } \\
\text { Tersedia }\end{array}$ & $\begin{array}{c}\text { Tidak } \\
\text { Tersedia }\end{array}$ \\
\hline $\begin{array}{l}\text { Trupark } \\
\text { Cirebon } \\
\text { Bangunan } \\
\text { Modern } \\
\text { Industrial }\end{array}$ & $\begin{array}{c}\text { Jelas } \\
\text { namun } \\
\text { konvensio } \\
\text { nal }\end{array}$ & $\begin{array}{c}\text { Cukup } \\
\text { jelas \& } \\
\text { terdesain }\end{array}$ & $\begin{array}{c}\text { Gedung } 2 \\
\text { lantai: } 7 \\
\text { ruang } \\
\text { pamer. } \\
\text { Layout dan } \\
\text { tampilan } \\
\text { sangat } \\
\text { unik \& } \\
\text { instagram } \\
\text { able }\end{array}$ & $\begin{array}{c}\text { Ruang } \\
\text { khusus } \\
\text { video } \\
\text { mappi } \\
\text { ng \& } \\
\text { ruang } \\
\text { video } \\
\text { proses } \\
\text { mem- } \\
\text { batik }\end{array}$ & $\begin{array}{c}\text { Ada } \\
\text { namun } \\
\text { kurang } \\
\text { signifikan } \\
\text { tetapi } \\
\text { menarik }\end{array}$ & $\begin{array}{c}\text { Harus } \\
\text { dengan } \\
\text { pemandu } \\
\text { karena } \\
\text { wajib }\end{array}$ & Tersedia \\
\hline $\begin{array}{c}\text { Batik } \\
\text { Pekalongan } \\
\text { Bangunan } \\
\text { antik } \\
\text { bersejarah }\end{array}$ & $\begin{array}{l}\text { Cukup } \\
\text { jelas, } \\
\text { terkesan } \\
\text { tua }\end{array}$ & $\begin{array}{c}\text { Kurang } \\
\text { jelas }\end{array}$ & $\begin{array}{c}\text { Gedung } \\
\text { dengan } 3 \\
\text { ruang } \\
\text { pameran \& } \\
1 \text { ruang } \\
\text { workshop } \\
\text { batik }\end{array}$ & $\begin{array}{c}\text { Tidak } \\
\text { ada }\end{array}$ & $\begin{array}{c}\text { Ada } \\
\text { namun } \\
\text { kurang } \\
\text { signifikan } \\
\text { membi- } \\
\text { ngungkan }\end{array}$ & $\begin{array}{l}\text { Tersedia, } \\
\text { sebaik- } \\
\text { nya } \\
\text { dengan } \\
\text { pemandu }\end{array}$ & $\begin{array}{c}\text { Tidak } \\
\text { tersedia }\end{array}$ \\
\hline
\end{tabular}




\begin{tabular}{|c|c|c|c|c|c|c|c|}
\hline $\begin{array}{c}\text { Batik } \\
\text { Yogyakarta } \\
\text { Bangunan } \\
\text { modern } \\
\text { biasa }\end{array}$ & $\begin{array}{l}\text { Cukup } \\
\text { jelas, } \\
\text { terkesan } \\
\text { tua }\end{array}$ & $\begin{array}{c}\text { Kurang } \\
\text { jelas }\end{array}$ & $\begin{array}{c}\text { Gedung } \\
\text { dengan } 3 \\
\text { ruang } \\
\text { pameran } \\
\text { dan } 1 \\
\text { ruang } \\
\text { workshop }\end{array}$ & $\begin{array}{c}\text { Tidak } \\
\text { ada }\end{array}$ & Tidak ada & $\begin{array}{l}\text { Tersedia, } \\
\text { sebaik- } \\
\text { nya } \\
\text { dengan } \\
\text { pemandu }\end{array}$ & Tersedia \\
\hline
\end{tabular}

Sumber: Rismantojo dan Valenska, 2019

Pada hasil dari tabel 1 dapat disimpulkan bahwa hampir semua museum tersebut masih menggunakan cara-cara pendekatan komunikasi yang konvensional. Seperti penjelasan materi pameran yang dicetak pada media kertas atau plastik, dengan tulisan yang cukup padat sehingga seringkali membosankan dan mata terasa capai. Banyak ditemukan penempatan materi keterangan benda pameran yang kurang nyaman karena letak yang terlalu bawah atau terlalu tinggi serta layout keterangan yang tidak ditata dengan baik. Sign system yang kurang didesain dengan penempatan yang kurang tepat sehingga dirasakan mubazir karena tidak memiliki fungsi dengan baik. Dari 4 museum di atas hanya Museum Trupark yang menyediakan media audio visual seperti pemutaran video di dalam auditorium sehingga memiliki keunggulan dibandingkan museum yang lainnya.

Dari keempat museum tersebut, alur pameran di Museum Tekstil Jakarta dirasakan paling kurang teratur dibandingkan museum-museum lainnya. Terutama pada gedung bagian galeri batik, penempatan display-display batik dirasakan terlalu berdekatan sehingga menyulitkan pengunjung untuk menikmati secara seksama keindahan dari batik-batik yang dipamerkan. Bahkan kaca-kaca pelindung pada display dirasakan mengganggu pandangan mata karena pantulan cahaya yang disebabkan oleh tata cahaya yang tidak tepat.

Museum Trupark dirasakan memiliki storyline yang lebih jelas karena alur/arah gerak pengunjung yang ditentukan oleh desain pameran sehingga seluruh bagian pameran akan dilewati oleh pengunjung. Beberapa museum 
menawarkan jasa guide yang memang sebaiknya digunakan karena penjelasan pada masing-masing barang yang dipamerkan kurang lengkap bahkan dengan bantuan guide baru dirasakan storyline yang dibangun secara verbal bukan oleh desain pamerannya.

Tiga museum diatas belum memanfaatkan teknologi media digital kecuali Museum Trupark yang sudah menggunakan teknologi video mapping di dalam ruang khusus dan menampilkan permainan visual dalam bentuk motion graphic yang diambil dari kombinasi motif-motif batik. Dari hasil observasi langsung ditemukan bahwa semua museum tersebut belum memanfaatkan teknologi AR. Sehingga media digital online yang dipakai baru website museum, Facebook dan Instagram.

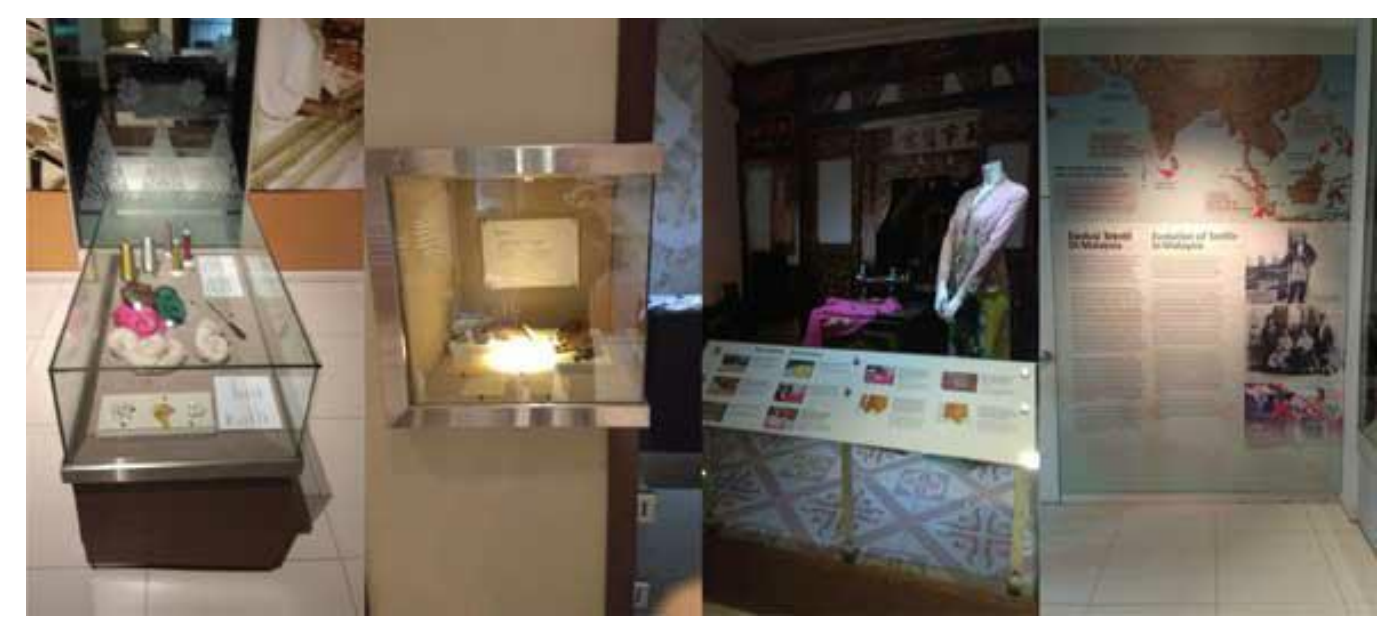

Gambar 6 National Textile Museum Kuala Lumpur Sumber: Rismantojo dan Valenska, 2018 


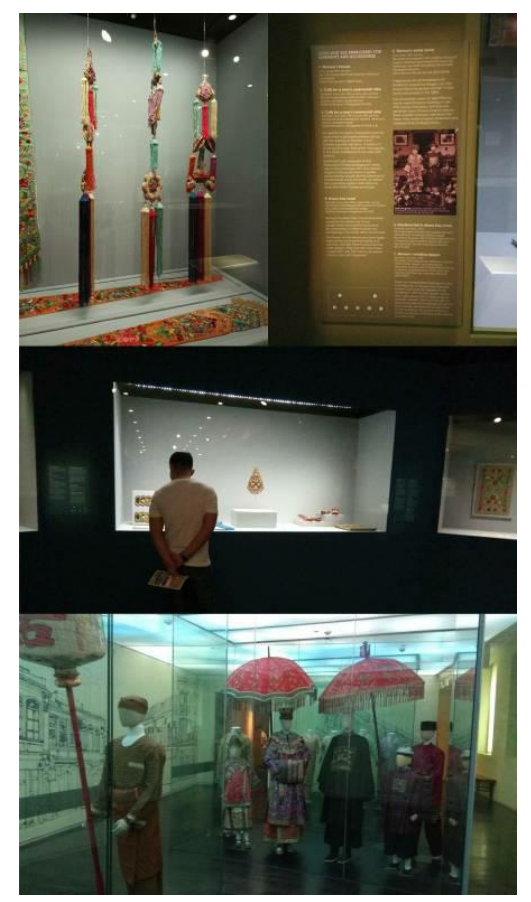

Gambar 7 Peranakan Museum Singapore Sumber: Rismantojo dan Valenska, 2018

Tabel 2 Perbandingan elemen desain museum bertema tekstil di luar negeri

\begin{tabular}{|c|c|c|c|c|c|c|c|}
\hline Museum & $\begin{array}{c}\text { Grafis } \\
\text { Informasi }\end{array}$ & Signage & $\begin{array}{l}\text { Layout } \\
\text { Gedung }\end{array}$ & $\begin{array}{l}\text { Media } \\
\text { Digital }\end{array}$ & $\begin{array}{c}\text { Story } \\
\text { telling }\end{array}$ & Guide & $\begin{array}{c}\text { Museum } \\
\text { Shop }\end{array}$ \\
\hline $\begin{array}{l}\text { National } \\
\text { Textile } \\
\text { Kuala } \\
\text { Lumpur } \\
\text { Bangunan } \\
\text { bersejarah } \\
\text { di Pusat } \\
\text { Kota }\end{array}$ & $\begin{array}{c}\text { Jelas } \\
\text { dengan } \\
\text { desain yang } \\
\text { baik }\end{array}$ & $\begin{array}{c}\text { Sangat } \\
\text { jelas dan } \\
\text { terdesain } \\
\text { baik }\end{array}$ & $\begin{array}{c}2 \text { lantai: } 4 \\
\text { ruang } \\
\text { pameran } \\
\text { dilayout } \\
\text { dengan } \\
\text { urutan } \\
\text { kepentingan } \\
\text { yang } \\
\text { menarik }\end{array}$ & $\begin{array}{l}\text { beberapa } \\
\text { layar } \\
\text { monitor } \\
\text { video } \\
\text { tetapi } \\
\text { tidak } \\
\text { berfungsi }\end{array}$ & $\begin{array}{l}\text { Jelas dan } \\
\text { cukup } \\
\text { menarik } \\
\text { dibantu } \\
\text { dengan } \\
\text { visualisa- } \\
\text { si yang } \\
\text { baik }\end{array}$ & Tersedia & Tersedia \\
\hline $\begin{array}{c}\text { Peranakan } \\
\text { Singapore } \\
\text { Bangunan } \\
\text { Antik } \\
\text { bersejarah } \\
\text { di Pusat } \\
\text { Kota }\end{array}$ & $\begin{array}{c}\text { Jelas } \\
\text { dengan } \\
\text { desain } \\
\text { yang baik }\end{array}$ & $\begin{array}{c}\text { Sangat } \\
\text { jelas dan } \\
\text { terdesain } \\
\text { baik }\end{array}$ & $\begin{array}{c}4 \text { lantai. } \\
\text { Layout } \\
\text { terdesain, } \\
\text { pengalaman } \\
\text { kunjungan } \\
\text { menyenang- } \\
\text { kan \& } \\
\text { memorable }\end{array}$ & $\begin{array}{l}\text { Hampir } \\
\text { di setiap } \\
\text { ruang } \\
\text { terdapat } \\
\text { monitor } \\
\text { video, } \\
\text { berfungsi } \\
\text { didesain } \\
\text { baik }\end{array}$ & $\begin{array}{l}\text { Tersusun } \\
\text { jelas dan } \\
\text { menarik }\end{array}$ & Tersedia & Tersedia \\
\hline
\end{tabular}

Sumber: Rismantojo dan Valenska, 2019 
Dari hasil obsevasi langsung pada tabel 2 kemudian dibandingkan dengan tabel 1 maka disimpulkan bahwa hampir semua museum-museum terutama yang berlokasi di Indonesia masih menggunakan cara-cara komunikasi visual yang konvensional. Kecuali Museum Trupark Cirebon yang sudah menggunakan digital media dalam bentuk video mapping di salah satu ruang pamer yang menjadi keunggulan dibanding museum yang lain. Museum Peranakan Singapore juga memanfaatkan media video sebagai bagian dari penjelasan yang menarik bagi pengunjung karena dibawakan dengan storyline yang menarik dan secara humoris. Dari semua museum yang dikunjungi, tidak ada satupun yang sudah memanfaatkan teknologi AR. Tetapi terdapat beberapa museum yang sudah mengembangkan storyline sebagai bagian penyampaian informasi yang menarik untuk mengikat minat pengunjung contohnya pada Museum Peranakan Singapore dan Museum Truepark Cirebon.

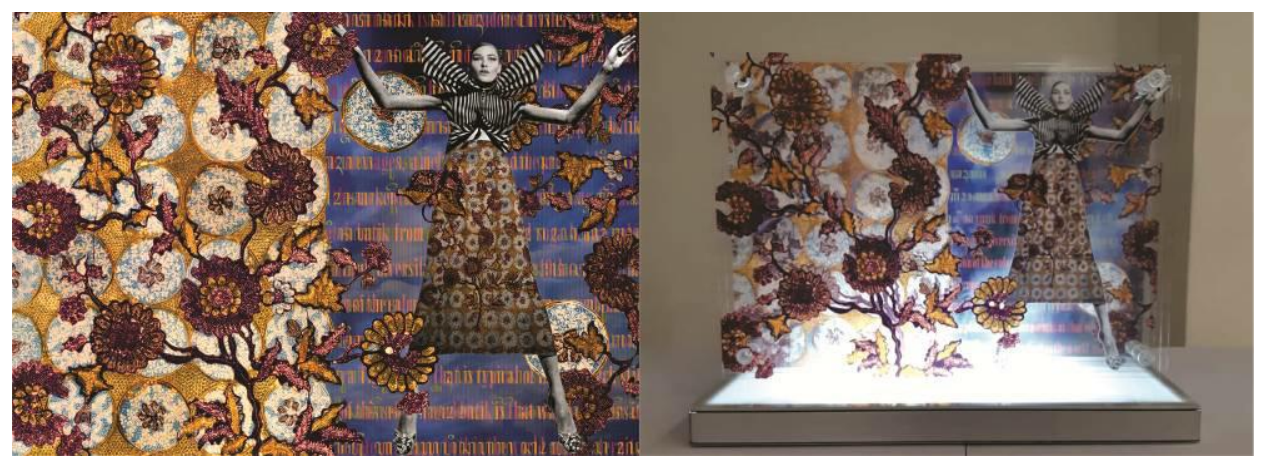

Gambar 9. Decoding\#1, digital print on acrylic 42 × 29,7 cm, 2019 oleh Sandy Rismantojo Sumber: Rismantojo dan Valenska, 2019

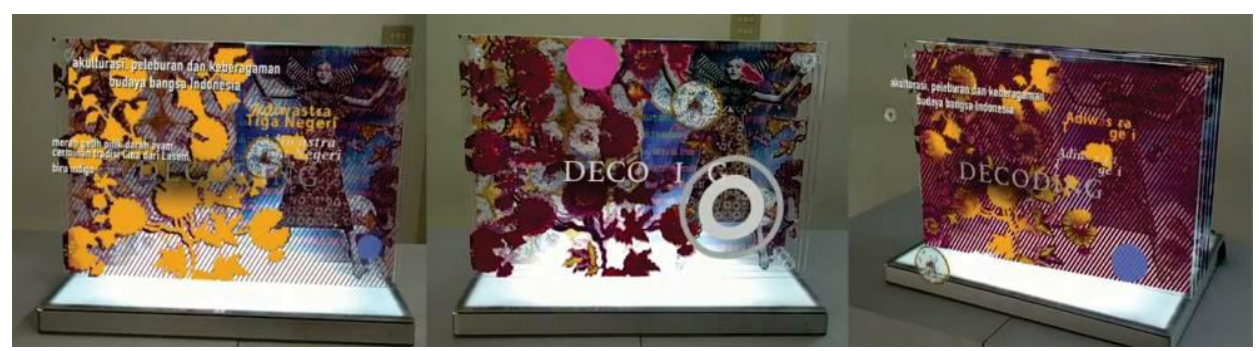

Gambar 10 Augmented Reality pada karya Decoding\#1 Sumber: Rismantojo dan Valenska, 2019 
Untuk online survey kedua dengan menggunakan Google Form, penulis meminta pendapat dari para mahasiswa/i UK Maranatha Program Studi Desain Komunikasi Visual yang sedang menempuh semester 1 hingga semester 7 mengenai karya seni Decoding\#1 yang dipamerkan pada acara pameran Internasional Unoflatu: Re-creation di Ruang Pamer Gedung B UK Maranatha Bandung. Konsep karya seni ini menggambarkan sehelai batik adalah kain yang bercerita atau bernarasi dalam bentuk karya visual yang merupakan hasil proses kreatif dan kreasi para pengrajin yang memiliki banyak makna baik tersirat maupun tersurat tergantung dari daerah mana batik tersebut dibuat. Karya ini seperti membedah visual-visual narasi tersebut ke dalam beberapa layer makna sehingga pengamat karya dapat menikmati bahwa batik bukan hanya selembar kain tetapi suatu mahakarya seni khas Indonesia.

Teknik dan material yang digunakan adalah digital printing pada 4 layer akrilik yang menggambarkan proses decoding batik tiga negeri karya Ibu Priscilla Renny dari Maranatha Ong's Art Batik Lasem. Dengan bekerja sama dengan seniman AR yaitu Kultse, teknologi AR diterapkan pada karya seni ini yang dapat dinikmati dengan menggunakan aplikasi Artitive. Para pengunjung dapat menikmati motion graphic hasil paduan visual dengan teks yang menjelaskan secara singkat mengenai karya seni ini yang dilengkapi dengan audio sebagai backsound.

Hasil dari survey tersebut adalah sebagai berikut, 92,2\% berpendapat AR akan membuat pengalaman mengunjungi museum menjadi lebih menarik dan tidak membosankan, 56,9\% menyatakan bahwa teknologi virtual reality dapat diterapkan untuk melengkapi teknologi AR. Serta 15\% berpendapat bahwa pemanfaatan motion graphic dan game juga dapat diterapkan dalam menjelaskan suatu karya yang dipamerkan. 96,1\% setuju bahwa dengan teknologi AR dapat 
membuat penyampaian informasi mengenai museum dan benda-benda pamer menjadi lebih menarik dan interaktif.

Masukan umum dari target audience mengenai penerapan AR pada karya ini adalah pengunjung merasakan dengan teknologi AR membuat pengalaman mengamati karya seni menjadi lebih seru karena dapat melihat karya seni dengan cara yang berbeda. Pengunjung merasa dapat berinteraksi dengan karya yang dipamerkan sehingga lebih mudah menerima informasi yang disajikan lebih modern dan tidak membosankan. Tetapi juga ada pendapat bahwa ada kekurangan dari AR ini, yaitu pengunjung cenderung malas untuk mengunduh aplikasi di smartphone mereka, mungkin lebih baik jika menyediakan tablet atau smartphone yang sudah ada aplikasi AR ini sehingga para pengunjung lebih tertarik dan mudah untuk melihatnya. Kesimpulan dari survey ini adalah teknologi AR dapat menjadi solusi untuk membuat pengalaman kunjungan ke museum menjadi lebih menyenangkan, interaktif dan menarik.

\section{KESIMPULAN}

Tidak bisa dipungkiri bahwa peran museum sangatlah penting dalam melestarikan sejarah dan kekayaan budaya bangsa agar dapat menjadi sumber acuan bagi generasi penerus dalam usaha mengembangkan dan memanfaatkannya untuk memajukan industri kreatif Indonesia. Oleh karena itu diperlukan kesadaran dari pihak pengelola museum beserta instansi-instansi terkait maupun pihak sponsor untuk mengembangkan suatu program yang menarik. Untuk membantu meningkatkan kunjungan ke museum dengan menargetkan generasi milenial maka hal utama yang harus dilakukan adalah memahami karakter generasi tersebut dan masuk ke dalam gadget yang digunakan oleh mereka. Selain itu museum juga harus berubah dari museum 
sebagai tempat yang hanya memberikan ilmu, menjadi museum yang memberikan gagasan-gagasan baru, menghibur dan selalu up to date.

Salah satu cara dalam meremajakan museum adalah dengan memanfaatkan kemajuan teknologi digital dalam hal ini adalah teknologi Augmented Reality (AR). AR merupakan teknologi yang sudah dapat dipercaya akan banyak memberikan keuntungan bagi pihak museum untuk meningkatkan pengalaman yang memuaskan para pengunjung. Teknologi ini cukup flexible dalam mengolah visual, suara, motion dan penggabungan antara tampilan benda asli dengan benda virtual sangat memungkinkan untuk dikembangkan. Dari hasil observasi langsung terhadap beberapa museum, dapat dilihat bahwa rata-rata museum tersebut masih konvensional yaitu museum sebagai tempat memberikan ilmu yang pasif atau dapat dikatakan kurang interaktif. Ada beberapa museum yang sudah cukup interaktif seperti Peranakan Museum Singapore yang mengintegrasikan permainan sederhana yang cukup menarik yaitu pengunjung mengumpulkan stamps di beberapa galeri pameran dengan menggunakan petunjuk-petunjuk yang tertera dalam brosur. Permainan. Museum saat ini harus lebih interaktif dengan memanfaatkan teknologi digital dengan mengintegrasikan dengan kekuatan dunia maya, dalam hal ini adalah virtual museum.

Dengan proses digitalisasi dapat membantu pihak museum dalam melakukan pendataan atau pendokumentasian benda-benda museum dalam bentuk 3D scanning dan 2D yang kemudian didesain ke dalam bentuk virtual museum. Dengan hal ini, materi museum dapat diakses langsung melalui jaringan internet atau melalui aplikasi android di smartphone. Oleh karena itu diperlukan keahlian dalam membangun storytelling yang menarik yang dapat mengikat hubungan antara dunia virtual (website) dan dunia nyata (yaitu bentuk fisik museum) sehingga membangun kesinambungan cerita. Namun harus diperhatikan pula tujuan dari museum virtual ini bukan untuk membuat kunjungan 
langsung ke museum menjadi tidak diperlukan. Tetapi justru berfungsi sebagai daya tarik bagi target untuk menikmati pengalaman unik yang menarik dan menyenangkan dengan mengunjungi langsung museum-museum tersebut.

Dengan memanfaatkan teknologi AR akan sangat membantu museum untuk menampilkan informasi dari benda-benda pamer menjadi lebih menarik dan interaktif. Terutama untuk museum-museum pribadi dan dalam skala kecil, teknologi ini dapat menghemat banyak biaya karena para pengunjung akan menggunakan smartphone mereka dan aplikasi yang sudah tersedia, museum tidak perlu menanam dana yang besar untuk pembelian perangkat-perangkat elektronik penunjang media digital seperti televisi atau layar besar, infocus, komputer dan lainnya. Sehingga dapat mengalihkan dana tersebut untuk mengembangkan visual informasi dalam bentuk digital dan menambah koleksi museum.

Dapat dinyatakan ke depan bahwa perkembangan teknologi AR akan banyak mempengaruhi interaksi di kehidupan kita, tidak hanya penggunaannya di museum tetapi juga di bidang-bidang lain seperti dunia bisnis, komersial, pendidikan dan bidang lainnya. Pengelola museum harus menyadari bahwa ekspektasi pengunjung sudah lebih dari hanya berkunjung dengan mengamati, membaca keterangan dan mengeksplorasi ruang, pengunjung mengharapkan pengalaman yang menarik, unik, memorable, dan berbeda. Hal ini dapat dicapai dengan menggunakan AR sebagai alat utama yang menghubungkan mereka dengan wujud fisik museum dan wujud virtual (online dan onsite) yang terjalin erat sehingga memberikan visitor experience yang memikat dan ilmu yang bermanfaat bagi generasi milenial sebagai pengunjung museum. 


\section{PERNYATAAN PENGHARGAAN}

Penelitian ini didukung dan didanai oleh dana hibah dari Kementerian Riset, Teknologi, dan Pendidikan Tinggi Republik Indonesia (Kemenristekdikti RI) 2017-2019 yang diberikan kepada Fakultas Seni Rupa dan Desain Universitas Kristen Maranatha. Penulis juga ingin mengucapkan terimakasih kepada Punjung Wratsongko (Kultse) yang telah bersedia membantu dalam mendesainkan motion graphic untuk Augmented Reality karya seni Decoding\#1.

\section{DAFTAR PUSTAKA}

Akbar, Ali. 2010. Museum di Indonesia, Kendala dan Harapan. Jakarta: Papas Sinar Sinanti dalam Nasution, Isman Pratama. 2014. Teori penyusunan Instrumen Penelitian Pengunjung Museum. Departemen Arkeologi FIB-Universitas Indonesia. Diunduh $24 \quad$ September 2019 dari http://ruslanabdullah61.wordpress.com/2014/03/16/instrumenpenelitian-pengunjung-museum/

Hui-Chuan, C., Chuan-Kun, H. \& Ming-Chyuan, H., 2006. A New Communication Model In The Natural History Museum. Intercom 2006 Conference Paper. Diunduh $24 \quad$ September 2019 dari https://www.academia.edu/1451800/A_New_Communication_Model_in _Natural_History_Museum

Djunaedi, E., 2015, 9 Oktober. Anak muda nggak minat ke museum, kalaupun berkunjung cuma buat selfie. [online] https://www.merdeka.com/travel/anak-muda-nggak-minat-ke-museumkalaupun-berkunjung-cuma-buat-selfie.html. Diunduh 1 September 2019.

Hong, J., Takahashi, J., Kusaba, M., \& Sugita, S. 1995. An Approach to the Digital Museum - Multimedia Systems for an Ethnology Museum. ICHIM, Multimedia Computing and Museums dalam Bertalya. 2014. Rancang Bangun Situs Museum dan Galeri Digital kain Tenun Songket Sumatera Sebagai Media Pelestarian dan Promosi Produk Lokal Sumatera. Laporan Akhir Penelitian Strategis Nasional, Universitas Gunadharma Jakarta.

Kotler, N. and Kotler, P. 1998. Museum Strategy and Marketing-Designing Missions, Building Audiences, Generating Revenue and Resources. San Francisco, Jossey-Bass Inc. U.S.A. dalam Nasution, Isman Pratama. 2014. Teori penyusunan Instrumen Penelitian Pengunjung Museum. Departemen 
Arkeologi FIB-Universitas Indonesia. Diunduh 24 September 2019 dari http://ruslanabdullah61.wordpress.com/2014/03/16/instrumenpenelitian-pengunjung-museum/

Kotler, N. and Kotler, P. 2000. Can Museums be all things to all people?: Missions, goals, and marketing's role. Museum Management and Curatorship, 18(3), 271-287

Kroll, M. 2016, July 13. What is AR? (augmented reality) [Web log post]. Diakses dari https://www.extension.org/2016/06/13/what-is-ar-augmentedreality/

Kementrian Pemberdayaan Perempuan dan Perlindungan Anak. 2018. Statistik Gender Tematik: Profil Generasi Milenial Indonesia.

Locker, Pam. 2011. Basic Interior Design 02: Exhibition Design. Singapore: AVA Publishing.

Marques, Diana Cristina Valente. n.d. The Visitor Experience Using Augmented Reality on Mobile Devices in Museum Exhibitions. Doctoral Program In Digital Media. Faculdade de Letras da Universidade do Porto.

Muntahanah, M., Toyib, R., \& Ansyori, Miko. 2017. Penerapan Teknologi Augmented Reality Pada Katalog Rumah Berbasis Android (Studi Kasus PT. Jashando Han Saputra). Jurnal Pseudocode, 4(1), 8189. https://doi.org/10.33369/pseudocode.4.1.81-89

Pekarik, Andrew J., Doering, Zahava D., and Karns, David A. 1999. Exploring Satisfying Experiences in Museums. Curator: The Museum Journal. 42 (2):152-173. https://doi.org/10.1111/j.2151-6952.1999.tb01137.x dalam Hui-Chuan, C., Chuan-Kun, H. \& Ming-Chyuan, H., 2006. A New Communication Model In The Natural History Museum. Intercom 2006 Conference Paper. Diunduh 24 September 2019 dari https://www.academia.edu/1451800/A_New_Communication_Model_in _Natural_History_Museum

Vaughan, Tay. 2004. Multimedia: Making It Work. 6th Edition. Diterjemahkan oleh Theresia Arie Prabawati dan Agnes Heni Triyuliana. Penerbit Andi: Yogyakarta. 